\title{
Effect of lipopenic and hypotensive treatment on homocysteine levels in type 2 diabetics
}

This article was published in the following Dove Press journal:

Vascular Health and Risk Management

12 May 2010

Number of times this article has been viewed

\section{Mabrouka El Oudi' \\ Zied Aouni' \\ Haroun Ouertani² \\ Chakib Mazigh ${ }^{2}$ \\ Salem Machghoul}

'Département de biochimie, ${ }^{2}$ Service d'endocrinologie, Hôpital militaire de Tunis, 1008 Montfleury, Tunisie
Correspondence: Mabrouka El Oudi Département de Biochimie, Hôpital militaire de Tunis, 1008 Montfleury, Tunisie Tel +2I62526I722

Email doc_mo@ymail.com
Aim: Evaluate the effect of lipopenic and hypotensive treatment on homocysteine levels.

Methods: We recruited 145 type 2 diabetics and 130 control subjects. Thirty-seven diabetics had no complications, 54 had microvascular complications and 54 had macrovascular complications. We determined the parameters homocysteine of lipid, vitamin B12, triglycerides, and folates for all subjects. Associated treatments used one or more of the following drugs, statin, fibrate, angiotensin-converting enzyme inhibitor and beta-blockers.

Results: Hyperhomocysteinemia was present in $35.6 \%$ of patients. Diabetics had elevated serum levels of triglycerides $(P<0.001)$, homocysteine $(P<0.01)$, folates $(P<0.01)$ and vitamin B12 $(P<0.001)$. A strong association was found between type 2 diabetes and hyperhomocysteinemia $(P<0.001)$. Diabetics with associated treatment had elevated homocysteine, vitamin B12 and folate levels when compared to diabetes-free controls. For diabetics with macrovascular complications, we found significant differences in homocysteine $(P=0.010)$ and folate $(P=0.014)$ between those taking associated drugs and those who did not. For diabetics with microvascular complications, a significant difference was found in folate only $(P=0.012)$.

Conclusion: Drugs used for hypertension and hyperlipidemia may have an effect on homocysteine levels, for this reason the interaction between drug action and homocysteine levels should be taken into consideration.

Keywords: type 2 diabetes, complications, homocysteine, hypolipemiant drug, hypotensive drug

\section{Introduction}

Type 2 diabetes mellitus constitutes a major public health problem that leads to the development of various chronic complications. Macrovascular disease represents the main cause of mortality in patients with diabetes. In fact, the damage of the endothelial wall plays an important role in the development of diabetic complications. Other multiple risk factors are considered in the assessment of chronic diabetic complications such as hyperglycemia, dyslipidemia, genetic factors, and oxidative stress. ${ }^{1}$ Recently there has been a focus on homocysteine (Hcy) as a new risk factor implicated in atherogenesis, in particular for diabetes. Hcy is a sulfhydryl amino acid involved in the metabolism of the essential amino acid, methionine. High levels of Hcy are considered to be related to many diseases and especially to cardiovascular complications. ${ }^{2,3}$ Elevated Hcy levels may contribute to the cardiovascular disease risk of type 2 diabetic patients. Hcy concentrations can change due to multiple factors such as vitamin levels, when reduced may cause hyperhomocysteinemia,${ }^{4,5}$ and mutations in genes coding for 
enzymes involved in Hcy metabolism. Other factors that may have an effect on Hcy levels include medicines (eg, theophilline, methotrexate $)^{6}$ and such diseases as hypothyroidism, kidney pathologies, cancers, and others. ${ }^{7}$

In the present study we evaluated the effect of the hypolipemiant and hypotensive treatment on homocysteine levels in type 2 diabetes.

\section{Material and methods Study group}

This case control study was performed in a group of 275 participants (145 type 2 diabetes and 130 control subjects). Type 2 diabetic patients were hospitalized in the Department of Endocrinology at the Military Hospital in Tunis. The recruit, was followed for 6 months. Patients with hypothyroidism or chronic renal disease were not included in this study. A questionnaire was performed for all participants and the information recorded included: personal, anthropometric, and lifestyle data (including smoking habits); clinical history; and data relevant to microvascular (retinopathy, blindness, nephropathy, and foot ulcers); and macrovascular complications (coronary heart disease [CHD] ed group, cerebral thromboembolism, and peripheral amputations); and laboratory data. Treatment for diabetes was defined as requiring drug treatment at admission (eg, insulin injection, or oral hypoglycemic agents). Treatments used for hyperlipidemia and hypertension were classified as, statin fibrate, inhibitor enzyme conversion, and beta-blockers. Associated treatment is defined as one or more of the cited drugs which were used by patients and noted at their admission, ie, patients taking drugs for prevention or as needed treatment. We classified diabetics into subgroups according to the presence or absence of vascular complications. Thirty-seven diabetics had no complications, 54 had microvascular complications, and 54 had macrovascular complications. The numbers of patients with associated treatment were 59 with diabetes, 35 were diabetics with macrovascular complications, and 26 were diabetics with microvascular complications.

The control group consisted of 130 selected subjects from various medical and paramedical individuals within the hospital. Subjects completed a large questionnaire before their participation. Only subjects without any complications or disease, which might influence Hcy levels and were not using any prescribed treatments were included in the study. None of the participants took any vitamin supplementation. All subjects accepted by the study signed a consent form provided by the hospital ethics committee.

\section{Laboratory analysis}

Blood was withdrawn from subjects after an overnight fast. The plasma was separated within one hour of sampling by centrifugation (3500 rpm/minute for 15 minutes). Aliquots for the determination of Hcy, folates (Fol), vitamin B12 (vitB12) were stored at $-20^{\circ} \mathrm{C}$ until analysis. Lipids were determined on the same day of collection. Total cholesterol (TC), triglycerides (TG) and high-density lipoprotein cholesterol (HDL-C) were measured by using a colorimetric enzymatic method in a Technicon automatic analyzer (RA-1000; Dade Behring, Los Angeles, CA). Total cholesterol was determined by end point colorimetric enzymatic method with cholesterol oxidase and peroxidase (Biomérieux, Marcy l'Etoile, France). HDL-C was determined by the same method after selective precipitation of low-density lipoprotein (LDL) and very low-density lipoprotein (VLDL). Triglycerides were determined by an end point colorimetric enzymatic method with lipase, glycerokinase, glycerophosphate oxidase and peroxidase (Biomérieux). LDL-C was calculated by Friedwald's formula:

$$
\mathrm{LDL}-\mathrm{C}=\mathrm{TC}-(\mathrm{HDL}-\mathrm{C}+\mathrm{TG} / 2.18) \text { for } \mathrm{TG}<4.5 \mathrm{mM} / \mathrm{L} \text {. }
$$

The blood for measuring total homocysteine (tHcy) was collected in tubes containing EDTA and were kept on ice until centrifuged (3500 rpm/minute for 15 minutes). The plasma was stored at $-20^{\circ} \mathrm{C}$ until assayed. The concentrations of tHcy in plasma were evaluated by using an automatic analyzer (Immulite 1000 DPC; Siemens Medical Solutions, Los Angeles, CA) based on a competitive immunoassay. The Hcy assay involves a preliminary manual pretreatment step; Hcy is released from its binding proteins and converted to S-adenosyl-homocysteine (SAH) by an off-line 30 minute incubation at $37^{\circ} \mathrm{C}$ in the presence of S-adenosyl-Lhomocysteine hydrolase and dithiothreitol (DTT). Vitamin B12 and folates were measured by an immunometric method using chemiluminescent markers (Immulite 2000 DPC; Siemens Medical Solutions).

\section{Statistical analysis}

Results were statistically analyzed by SPSS software (v. 10.0 for Windows; SPSS Inc., Chicago, IL) Continuous variables are presented as means \pm standard deviation (SD), and qualitative variables as relative frequencies. Kolmogorov-Smirnov test for the normality of different parameters showed a normal distribution only for some parameters. We used a $t$-test to compare quantitative variables and a Chi-square test to compare qualitative variables. The odds ratio was used to assess the relative risk with a confidence interval at $95 \%$. Correlation 
between variables was determined by Spearman test. The differences were significant if $P$ value was less than 0.05 .

\section{Results}

Characteristics of the study population are shown in Table 1. Diabetic patients had elevated TC, LDL-C, TG, tHcy, Fol and vitB12 with significant differences in TG $(P<0.001)$, tHcy $(P<0.01)$, Fol $(P<0.01)$ and $\operatorname{VitB12}(P<0.001)$ compared to controls. Significant negative correlation was found between Hcy and folates $(\mathrm{r}=-0,23 ; P<0.01)$ (Table 1).

Hyperhomocysteinemia $(\mathrm{Hcy}>15 \mu \mathrm{M} / \mathrm{L})$ was present in $35.6 \%$ of patients. The mean Hcy was significantly higher in type 2 diabetic patients than in the control group (Table 1). Men had significantly higher Hcy as compared to women only in the control group $(P<0.05)$ (Table 2).

A significant difference between patients taking associated treatment and those who did not was noted Fol $(P<0.01)$ (Table 3).

In order to evaluate the association between hyperhomocysteinemia and type 2 diabetes a Chi-square test was performed; in this we found a strong association $(P<0.001)$.

When we subdivided patients according to the type of complication we found that diabetics with macrovascular complication had elevated tHcy levels $(15.06 \pm 7.94 \mu \mathrm{M} / \mathrm{L})$ when compared to those with microvascular complications $(13.90 \pm 7.53 \mu \mathrm{M} / \mathrm{L})$ and those with no complications $(12.64 \pm 6.55 \mu \mathrm{mol} / \mathrm{L}$ ). The odds ratio (OR) was 2.5 (with a $95 \%$ confidence interval $[\mathrm{CI}]: 0.94-6.61 ; P=0.05)$ and 1.69, (95\% CI: $0.62-4.59 ; P=0.21)$ for macrovascular and microvascular complications respectively.

Table I Clinical and biological characteristics of the study group

\begin{tabular}{|c|c|c|c|}
\hline & Control subjects & Type 2 diabetics & $P$ \\
\hline $\begin{array}{l}\text { Number } \\
\text { (men/women) }\end{array}$ & $130(74 / 56)$ & $145(75 / 70)$ & - \\
\hline Age (years) & $50.14 \pm 7.99$ & $56.36 \pm 11.57$ & NS \\
\hline BMI $\left(\mathrm{kg} / \mathrm{m}^{2}\right)$ & $25.63 \pm 3.63$ & $28.61 \pm 5.12$ & $<0.001$ \\
\hline Tobacco (\%) & 33.1 & 38.1 & NS \\
\hline $\begin{array}{l}\text { Total cholesterol } \\
(\mathrm{mM} / \mathrm{L})\end{array}$ & $4.66 \pm 1.06$ & $4.93 \pm 1.17$ & NS \\
\hline LDL-C (mM/L) & $3.08 \pm 0.95$ & $3.13 \pm 0.98$ & NS \\
\hline HDL-C (mM/L) & $1.13 \pm 0.30$ & $1.12 \pm 0.29$ & NS \\
\hline TG (mM/L) & $\mathrm{I} .04 \pm 0.64$ & $1.48 \pm 0.93$ & $<0.001$ \\
\hline Hcy $(\mu \mathrm{ML})$ & $11.65 \pm 4.73$ & $14.26 \pm 7.54$ & $<0.01$ \\
\hline Fol (ng/mL) & $6.52 \pm 4.45$ & $8.98 \pm 7.23$ & $<0.01$ \\
\hline VitBI2 (pg/mL) & $267.75 \pm 112.25$ & $375.08 \pm 262.30$ & $<0.001$ \\
\hline
\end{tabular}

Abbreviations: BMI, body mass index; LDL-C, low-density lipoprotein cholesterol; HDL-C, high-density lipoprotein cholesterol; TG, triglycerides; Hcy, homocysteine; Fol, folate; VitBI2, vitamin BI2; NS, nonsignificant.
Table 2 Comparison of homocysteine levels between men and women

\begin{tabular}{llll}
\hline & Number & Homocysteine $(\mu \mathrm{mol} / \mathrm{L})$ & $\boldsymbol{P}$ \\
\hline Men & & & \\
Control & 74 & $12.41 \pm 4.53$ & 0.037 \\
Case & 75 & $14.63 \pm 7.72$ & $\mathrm{~N} 5^{*} 0.035^{\S}$ \\
& & & \\
Women & & & \\
Control & 56 & $10.63 \pm 4.84$ & 0.007 \\
Case & 70 & $13.84 \pm 7.36$ &
\end{tabular}

Note: Comparison of men to women *in the study group, ${ }^{\delta_{i}}$ the control group. Abbreviations: NS, not significant.

We found that diabetics treated with insulin $(\mathrm{n}=39)$ had elevated Hcy compared to those not treated with insulin $(\mathrm{n}=80)(16.17 \pm 8.45 \mu \mathrm{M} / \mathrm{L}$ versus $12.57 \pm 6.46 \mu \mathrm{M} / \mathrm{L}$; $P<0.05)$.

In diabetics with macrovascular complications we found significant differences in Hcy and Fol levels between diabetics taking associated drugs and those who did not. For diabetics with microvascular complications, we only found a significant difference in Fol levels (Table 4).

\section{Discussion}

Hyperhomocysteinemia is now established as a risk factor for cardiovascular disease, especially in diabetic patients. In our study $35.6 \%$ of patients had hyperhomocysteinemia, with higher Hcy levels in men. Sadeghian and colleagues ${ }^{8}$ found that plasma tHcy levels in men were significantly higher than in women and that the male gender was an effective factor in Hcy plasma levels. Influence of tobacco smoking on Hcy levels has been reported in literature. Such studies demonstrated a positive effect of tobacco on Hcy levels. ${ }^{9,10}$ In our study we did not find any significant difference in Hcy levels between smokers and nonsmokers, and neither in diabetics nor in control subjects despite elevated Hcy levels

Table 3 Effect of the associated treatment on homocysteine levels in diabetic patients

\begin{tabular}{llll}
\hline & $\begin{array}{l}\text { Type 2 diabetics } \\
\text { with associated } \\
\text { treatment } \\
\text { GI(59) }\end{array}$ & $\begin{array}{l}\text { Type 2 diabetics } \\
\text { without associated } \\
\text { treatment } \\
\text { G2 (76) }\end{array}$ & P \\
\hline Hcy $(\mu \mathrm{M} / \mathrm{L})$ & $15.22 \pm 7.52$ & $13.02 \pm 7.43$ & 0.094 \\
Folates $(\mathrm{ng} / \mathrm{mL})$ & $7.55 \pm 6.04$ & $10.88 \pm 8.22$ & 0.009 \\
VitBI2 $(\mathrm{pg} / \mathrm{mL})$ & $412.80 \pm 270.54$ & $324.57 \pm 244.16$ & 0.057 \\
\hline
\end{tabular}

Note: Associated treatment is one or more of the following: statin, fibrate, inhibitor enzyme conversion, and beta-blockers.

Abbreviations: $\mathrm{Hcy}$, homocysteine; Fol, folate; $\mathrm{VitB}$ I2, vitamin $\mathrm{B} / 2$. 
Table 4 Comparison between diabetics with associated treatment and those without in macro- and microvascular complicated subgroups

\begin{tabular}{llll}
\hline & SG I & SG2 & $P$ \\
\hline $\begin{array}{l}\text { Macrovascular } \\
\text { complications }\end{array}$ & $\mathbf{( 3 5 )}$ & $\mathbf{( 1 5 )}$ & \\
Hcy $(\mu \mathrm{M} / \mathrm{L})$ & $16.91 \pm 7.56$ & $10.84 \pm 6.76$ & 0.010 \\
Fol $(\mathrm{ng} / \mathrm{mL})$ & $8.89 \pm 6.81$ & $15.99 \pm 12.01$ & 0.014 \\
VitBI2 $(\mathrm{pg} / \mathrm{mL})$ & $467.26 \pm 255.45$ & $345.07 \pm 268.16$ & $\mathrm{NS}$ \\
Microvascular & $\mathbf{( 2 6 )}$ & $\mathbf{( 1 7 )}$ & \\
complications & & & \\
Hcy $(\mu \mathrm{mol} / \mathrm{L})$ & $14.56 \pm 7.77$ & $12.69 \pm 7.66$ & $\mathrm{NS}$ \\
Fol $(\mathrm{ng} / \mathrm{mL})$ & $5.48 \pm 4.83$ & $10.19 \pm 5.48$ & 0.012 \\
VitBI2 $(\mathrm{pg} / \mathrm{mL})$ & $349.92 \pm 296.44$ & $347.37 \pm 225.55$ & $\mathrm{NS}$ \\
\hline
\end{tabular}

Notes: SG I, subgroup of diabetes with associated treatment; SG 2, subgroup without associated treatment.

Abbreviations: NS, not significant; Hcy, homocysteine; Fol, folate; VitBI2, vitamin $\mathrm{BI} 2$.

in smokers. In the present study we found elevated tHcy levels in diabetic patients and that there was an association between hyperhomocysteinemia and type 2 diabetes. This result is inline with those of other case control studies. ${ }^{11,12}$ Such elevated tHcy levels have been shown to be associated to cardiovascular disease (CVD) in most studies. Hoogeveen and colleagues ${ }^{13,14}$ reported an increased mortality due to CVD in diabetic patients with elevated tHcy concentrations. In a recently published study, by this laboratory we found that hyperhomocysteinemia is an independent risk factor for CVD incidence in diabetic patients. ${ }^{15}$ In the present study we found that diabetics with macrovascular complications had elevated tHcy levels when compared to those with microvascular complications. Buysschaert and colleagues ${ }^{16}$ found a higher incidence of macroangiopathy and nephropathy in a group of diabetics with hyperhomocysteinemia. Indeed such studies have reported the effect of diabetes treatment on the tHcy levels. Otmane and colleagues ${ }^{17}$ found that tHcy levels were higher in patients treated with sulfonamide than those treated with metformin. These results are in contrast with those found by Sahin and colleagues ${ }^{18}$ who demonstrated that metformin in type 2 diabetes increases Hcy levels, whereas rosiglitazone decreases Hcy level in the same time period. In a study by Derosa and colleagues ${ }^{19}$ glimepiride was shown to have had a lowering effect on thcy levels whereas metformin did not. ${ }^{20}$ These drugs exacerbated vitamin B12 and folate deficiency, which is not the case in our study, as diabetic patients had elevated vitamin B12 and folate levels. This can be explained in part that elevated Hcy levels in diabetic patients may be due to an unknown factor in our study, possibly in the treatment the diabetics received. Some authors suggest that lower folic acid concentrations observed in diabetic patients may be explained in terms of hyperglycemia increasing soluble vitamin secretion. ${ }^{21}$ Evidence from another study suggests that insulin and sulfonylurea treatment do not alter plasma tHcy. ${ }^{22}$ Rudy and colleagues ${ }^{23}$ did not found any significant difference between diabetic patients who were administered insulin and those who were administered oral agents. In our study, we found that diabetics treated with insulin had elevated tHcy levels when compared to those not treated with insulin, (independent of oral agents). Indeed insulin has important effects on protein and amino acid metabolism. However, its effect on Hcy metabolism has not been well studied. During a hyperinsulinemic euglycemic clamp, plasma tHcy levels fell by approximately $20 \%$ in normal subjects but did not do so in insulin resistant patients with type 2 diabetes. ${ }^{24}$ These data suggest that plasma homocysteine concentrations are regulated by acute hyperinsulinemia in normal subjects but not in insulin-resistant diabetic patients.

Diabetics with macrovascular complications in our study had the elevated tHcy levels and that those with associated treatment (drugs for CVD prevention, hypertension or dyslipidemia) also had elevated tHcy levels when compared to those without associated treatment. In fact, beyond their effect on lipids certain drugs such as fenofibrate may affect other markers of CVD risk. ${ }^{25}$ The elevation of tHcy levels after fenofibrate treatment may show a modest effect of fenofibrate on the reduction of CVD risk. ${ }^{26}$ Mayer and colleagues $^{27}$ demonstrated that fenofibrate decreases LDL-C but in contrast to fluvastatin has no significant antioxidative and endothelium-protective potential, probably due to a concomitant increase of tHcy. Miltiadous and colleagues ${ }^{28}$ demonstrated statins have no effect on Hcy levels, and that their antiatherogenic properties (other than their cholesterol lowering effect) are not due to any change in Hcy plasma levels. However, in a recent study by Lin and colleagues ${ }^{29}$ statins could directly reduce Hcy-induced endothelial mononuclear cell (MNC) adhesion via vascular cell adhesion molecule-1 (VCAM-1) inhibition, suggesting its potential implication in Hcy-related atherosclerosis disease. In another study, statins may be an appropriate management option for polycystic ovary syndrome patients with hyperhomocysteinemia. ${ }^{30}$

It is important to determine whether lowering Hcy levels will prevent the onset of vascular disease in diabetic patients. Vitamin therapy may be necessary to correct hyperhomocysteinemia in many patients. In fact, several investigators have reported the role of vitamin therapy in lowering elevated tHcy concentrations. ${ }^{31,32}$ However, the role of vitamin therapy in decreasing the risk of vascular 
events is still unclear. A recent Vitamin Intervention for Stroke Prevention study failed to show any clinical effect on stroke prevention, ${ }^{33}$ whereas Bazzano and colleagues ${ }^{34}$ in a recent clinical study demonstrated that folic acid supplementation may reduce congenital heart defects in offspring. Although there is doubt about the role of vitamin therapy and the effect of drugs for the treatment of vascular disease on Hcy levels, we should not discontinue these treatments.

One of the limitations of our study was the small sample of patients taking associated treatment, because of this we did not sub-classify them according to individual drug treatment.

In conclusion, we can conclude that drugs used for hypertension and hyperlipidemia may have an effect on homocysteine levels which in turn could precipitate the proliferation of chronic complications, especially macrovascular ones. The duration of the drugs used may also have an effect on homocysteine and that is why we should take in consideration such interactions; to determine the precise action and metabolism by which homocysteine has such an effect on vascular diseases.

\section{Disclosure}

The authors report no conflict of interest relevant to this work.

\section{References}

1. Stratton IM, Adler AI, Neil HA, et al. Association of glycaemia with macrovascular and microvascular complications of type 2 diabetes (UKPDS 35):prospective observational study. BMJ. 2000;321(7258): 405-412.

2. Simon DI, Fless GM, Scanu AM, Loscalzo J. Tissue type plasminogenactivator binds to and is inhibited by surface-bound Lp (a) and LDL. Biochemistry. 1991;30:6671-6677.

3. Cattaneo M. Hyperhomocystéinémie et thrombose. J Dade Behring. 2003;6-14

4. Klee GG. Cobalamin and folate evaluation measurement of methylmalonic acid and homocysteine vs vitamin B12 and folate. Clin Chem. 2000;46:1277-1283.

5. Colombier A, DufloLeray A, Basuyau JP. Evaluation analytique du dosage de la vitamine B12 et des folates sur IMMULITE 2000. Immuno-analyse et Biologie Spécialisée. 2002;1:40-47.

6. Robinson K, Mayer EL, Miller DP, et al. Hyperhomocysteinemia and low pyridoxal phosphate. Circulation. 1995;92:2825-2830.

7. Medina MA, Amores-Sanchez MI. Homocysteine: an emergent cardiovascular risk factor? Eur J Clin Invest. 2000;30:754-762.

8. Sadeghian S, Fallahi F, Slarifar M, et al. Homocysteine, vitamin B12 and folates levels in premature coronary artery disease. BMC Cardiovasc Disord. 2006;6:38.

9. Graham IM, Daly LE, Refsum HM, et al. Plasma homocysteine as a risk factor for vascular disease: the European Concerted Action Project. JAMA. 1997;277:1775-1787.

10. Robinson K, Mayer EL, Miller DP, et al. Hyperhomocysteinemia and low pyridoxal phosphate: common and independant reversible risk factors for coronary artery disease. Circulation. 1995;92: 2825-2830.
11. Chico A, Perez A, Cordoba A, et al. Plasma homocysteine is related to albumin excretion rate in patients with diabetes mellitus: a new link between diabetic nephropathy and cardiovascular disease? Diabetologia. 1998;41:684-693.

12. Soinio M, Marniemi J, Laakso M, Lehto S, Ronnemaa T. Elevated plasma homocysteine level is an independent predictor of coronary heart disease events in patients with type 2 diabetes mellitus. Ann Intern Med. 2004;140:94-100.

13. Hoogeveen EK, Kostense PJ, Beks PJ, et al. Hyperhomocysteinemia increases risk of death especially in type 2 diabetes. Circulation. 2000;101:1506-1510.

14. Hoogeveen EK, Kostense PJ, Beks PJ, et al. Hyperhomocysteinemia is associated with an increased risk of cardiovascular disease, especially in non-insulin-dependent diabetes mellitus: a population-based study. Arterioscler Thromb Vasc Biol. 1998;18:133-138.

15. Aouni Z, Oudi M, Mazigh C, et al. Homocysteinaemia and degenerative complications in non insulin dependent diabetes mellitus. Tunis Med. 2005;83:537-540.

16. Buysschaert M, Dramais AS, Wallemacq PE, Hermans MP. Hyperhomocysteinemia in type 2 diabetes: relationship to macroangiopathy nephropathy and insulin resistance. Diabetes Care. 2000;12:1816-1822.

17. Otmane A, Makrelouf M, Bouchama Rim, Boucelma M, Berrah A, Zenati A. Dosage de l'homocystéine totale dans une cohorte de diabétiques de type 2. Revue Francophone des Laboratories. 2007; N396.

18. Sahin M, Tutuncu NB, Ertugrul D, Tanaci N, Guvener ND. Effects of metformin or rosiglitazone on serum concentrations of homocysteine, folate, and vitamin B12 in patients with type 2 diabetes mellitus. J Diabetes Complications. 2007;21:118-123.

19. Derosa G, Franzetti I, Chwatko G, Bald E. Total plasma homocysteine levels in type 2 diabetes patients. Diabetes Nutr Metab. 2000;13: 312-324.

20. Hoogeven EK, Kostense PJ, Jacobs C, Bouter LM, Hein RJ, Stehouwer CDA. Does metformin increase the serum total homocysteine level in non insulin dependant diabetes mellitus? J Intern Med. 1997;242:389-394.

21. Mooradian AD, Failla M, Hoohwerf B, Maryniuk M, WylieRosett J. Selected vitamins and minerals in diabetes. Diabetes Care. 1994;17:464-479.

22. Araki A, Sako Y, Ito H. Plasma homocysteine concentrations in Japanese patients with non insulin dependant diabetes mellitus: effect of parenteral methylcobalamin treatment. Atherosclerosis. 1993;103:149-157.

23. Rudy A, Kowalska I, Straczkowski M, Kinalska I. Homocysteine concentrations and vascular complications in patients with type 2 diabetes. Diabetes Metab. 2005;31:112-117.

24. Fonseca VA, Mudaliar S, Schmidt B, Fink LM, Kern PA, Henry RR. Plasma homocysteine concentrations are regulated by acute hyperinsulinemia in nondiabetic but not type 2 diabetic subjects. Metabolism. 1998;47:686-689.

25. Bissonette R, Treacy E, Rozen R, Boucher B, Cohn JS, Geneset J. Fenofibrate raises plasma Hcy levels in the fasted and fed states. Atherosclerosis. 2001;155:455-462.

26. Vergès B. FIELD deux ans après: quelle place pour les fibrates dans le diabète de type 2? Médecine des Maladies Métaboliques. 2008;2:32-37.

27. Mayer O Jr, Simon J, Holubec L, Pikner R, Trefil L. Folate co-administration improves the effectiveness of fenofibrate to decrease the lipoprotein oxidation and endothelial dysfunction surrogates. Physiol Res. 2006;55:475-481.

28. Miltiadous G, Papakostas J, Chasiotis G, Seferiadis K, Elisaf M. Statins and homocysteine. Atherosclerosis. 2003;166:199-200.

29. Lin CP, Chen YH, Lin WT, et al. Direct effect of statins on homocysteine-induced endothelial adhesiveness: potential impact to human atherosclerosis. Eur J Clin Invest. 2008;38:106-116.

30. Kaya C, Cengiz SD, Berker B, Demirtas S, Cesur M, Erdogan G. Comparative effects of atorvastatin and simvastatin on the plasma total homocysteine levels in women with polycystic ovary syndrome: a prospective randomized study. 2008;92(2):635-642. 
31. Clarke R, Collins R. Can dietary supplements with folic acid or vitamin B6 reduce cardiovascular risk? Design of clinical trials to test the homocysteine hypothesis of vascular disease. J Cardiovasc Risk. 1998;5:249-255.

32. Angeles $\mathrm{G}$, Katherine $\mathrm{Z}$. Homocysteine and cognitive function in elderly people. CMAJ. 2004;171:897-904.
33. Ntaios GC, Savopoulos CG, Chatzinikolaou AC, Kaiafa GD, Hatzitolios A. Vitamins and stroke:the homocysteine hypothesis still in doubt. Neurologist. 2008;14:2-4.

34. Bazzano LA. Folic acid supplementation and cardiovascular disease: the state of the art. Am J Med Sci. 2009;338:48-49.

\section{Publish your work in this journal}

Vascular Health and Risk Management is an international, peerreviewed journal of therapeutics and risk management, focusing on concise rapid reporting of clinical studies on the processes involved in the maintenance of vascular health; the monitoring, prevention and treatment of vascular disease and its sequelae; and the involvement of metabolic disorders, particularly diabetes. This journal is indexed on PubMed Central and MedLine. The manuscript management system is completely online and includes a very quick and fair peer-review system, which is all easy to use. Visit http://www.dovepress.com/ testimonials.php to read real quotes from published authors.

Submit your manuscript here: http://www.dovepress.com/vascular-health-and-risk-management-journal 